\title{
Reviewing the Trend in Image Processing Techniques Used in the Agriculture Industry.
}

\author{
Smriti Sridhar ${ }^{1}$, Rajiv Gupta ${ }^{2}$, Garrick Louis ${ }^{3}$ \\ ${ }^{1}$ MS Student, Department of System Engineering, University of Virginia, Charlottesville, USA. \\ ss4vh@virginia.edu \\ ${ }^{2}$ Senior Professor, Department of Civil Engineering, BITS Pilani, Rajasthan, India. \\ rajiv@pilani.bits-pilani.ac.in \\ ${ }^{3}$ Associate Professor, Department of Engineering Systems and Environment, Charlottesville, University of Virginia, USA \\ gel7f@virginia.edu
}

\begin{abstract}
Agriculture is the backbone of the global economy. With the increasing pressure and demand on agricultural systems to make the industry smarter, there is a need to focus on the void to be filled. A first step to achieving the sustainable development goals in farming, can be to leverage remote sensing to maximize the efficiency on the farm. In this paper, a comprehensive review is dedicated to the state of the art of image processing techniques used in agricultural applications and later encouraging the use of Artificial Neural Networks for more precise feature extraction. The works that we analyze can be categorized in the following application domains of precision farming: a. Crop/Vegetation management b. Land management c. Soil management. With fields growing larger, better monitoring systems are needed for automated management to reduce expenses. Hence, by applying Artificial Intelligence (AI)-powered solutions, farmers will be able to do more work with less effort and improved quality. This paper reviews the concepts, tools and the potential solutions to the agriculture industry and the need for better image processing techniques in remote sensing.
\end{abstract}

Keywords: Deep Learning, Machine learning, image processing, Remote sensing.

\section{Introduction}

While AI sees a lot of direct applications across sectors, it can also bring a paradigm shift in how we see farming today. From detecting plant diseases to predicting the crops that can deliver the best returns, artificial intelligence can help with one of the biggest challenges in agricultural domain: feeding an additional 2 billion people by 2050. [1] Applications of image processing in agriculture can be broadly classified into two categories: firstly, depending on the image understanding techniques and the second is based on the application of the same in the agricultural domain. This review mainly focuses on the trends of image processing methodologies in various domains of agriculture through these years and how they can be modified for the better. We perceive an image's content based on objects. Once having perceived objects, we link them together by means of a complicated network made up by experience and knowledge. This very step was hardly implemented in image interpretation software or any other modelling used in the state-of-the-art techniques. The image analysis presented here implies dealing with and handling image semantics. In most cases, information important for the understanding of an image is not represented in single pixels but in meaningful image objects and their mutual relations. Procedures for image object extraction which are able to dissect images into sets of useful image objects are therefore a prerequisite for the successful automation of image interpretation. In this paper, we aim to juxtapose three major areas: AI, agriculture, and image processing to analyze the trends in their applications on the agro-industry over these years. To achieve this, first, a study of image processing techniques used in major spatial and spectral feature extraction is conducted. Lastly, we encourage the use of Artificial Neural Network (ANN) models in other applications. The structure of the presented work is as follows: Section 2 depicts the current trends in image processing-based methodologies used. Section 3 gives an overview of the literature on the applications of AI based image processing techniques (mentioned in the previous section) to find agricultural objects of interest for better precision farming. Finally, in Section 4, the concluding inferences and future expectations in the domain. 


\section{Advances in Image Processing}

As stated above, the strong motivation to develop techniques for the extraction of image objects comes from the fact that most image data exhibit a characteristic texture which is neglected in common classification methods. The texture of an image can be defined in terms of its smoothness or coarseness. One field of image processing in which the quantification of texture plays a crucial role is that of industrial vision. One of the native ways to carry out the observations is by image segmentation into homogenous areas. [2] With a comprehensive literature review on the trends of image processing techniques used on the aforementioned application areas in agriculture, there is a need to observe the advancements to be used while processing the images. With the advent of better sensors, we have image data with better resolution. The problem of mixed pixels still remains as we have sensors with certain spatial resolution for each one of them. In order to overcome the limitation, we have to use precise classification methods, to extract pixel by pixel feature information. One such method used earlier was linear mixture model (LMM), which assumes the spectral reflectance of each pixel in an image to be a linear combination of the spectra of these end members weighted by their respective areal proportions within the pixel [3]. The limitations of using such a method is to expect an accurate end member spectrum and the surface component should be assumed to be opaque. In order to better the accuracy for classification of images, we can also use fuzzy sets. The fuzzy classifiers depict the degree of membership of pixels in an image to the user defined categories. Popular fuzzy set-based approaches are the fuzzy c-means clustering [4], the probabilistic c-means clustering [5] as well as the fuzzy supervised classification introduced by Wang [6]. The main drawback of using the fuzzy based classification is, if in the absence of training data, we try to detect the fuzziness, as this will give a membership bias to the trained classes. Finally, the third advanced method to improve the image classification process is the use of neural network-based classifiers to train a model to match the known class spectra pattern to produce an output layer with reduced errors. For the classification problems of specific objects in the image using neural networks have proven to be more accurate than conventional methods [7], [8], [9].

\section{Segmentation for Image Classification}

Human vision generally tends to divide images into homogeneous areas first, and characterizes those areas more carefully later [11]. Following the above hypothesis, dividing the image into meaningful objects of the land surface will result in more intuitive feature extraction. Segments in an image will never be able to represent meaningful objects of interests in all the scales and will be questionable for multi resolution images. Segmentation also requires a considerable amount of human effort to carefully divide the image onto the objects of interests which are intuitive and subjective to the user. The segmentation techniques can be divided into edge- and region-based sub methods, described below. There are chances of uncertainties to arise from such elements as measurement error, inherent variability, instability, conceptual ambiguity and over-abstraction [10] depict four aspects which can cause uncertainty in the image classification by segmentation, namely fuzziness, multiple criteria, spatially incomplete definitions and time incoherence. Gahegan 1999 [12] discussed the uncertainties in the procedure of image classification.

a. Edge based segmentation

This type of segmentation technique is based on the representativeness of each pixel with respect to its neighboring pixels. To carry out image segmentation, the vectored minima of the representativeness delimit areas consisting of pixels with similar spectral features (spatial segments). Later, standardization is performed by calculating the convergence index for every pixel in a specific window. [13]

Region based segmentation

In this type of segmentation, we cluster pixels starting with seed points and divide into regions until a certain threshold is reached. This threshold is generally the combination of size and homogeneity. This process continues until the entire image gets segmented. This type of method depends on a set of given seed points. The first step is to extract the characteristics and spatial features from a textured input image and in the optimization stage, grouping them into homogeneous segments by minimizing quality measure. This can be achieved by clustering based cost functions given in. [14], [15] and [16]. 


\section{Artificial Neural Networks (ANN) for Image Classification}

Artificial Neural Networks (ANNs) are inspired by the human brain functionality, emulating complex functions such as pattern generation, cognition, learning, and decision making [17]. The human brain consists of billions of neurons that intercommunicate and process any information provided. Similarly, an ANN is a simplified model of the structure of the biological neural network, consisting of interconnected processing units organized in a specific topology. Deep ANNs are most widely referred to as deep learning (DL) or deep neural networks (DNNs) [18]. One of the main advantages of DL is that in some cases, the step of feature extraction is performed by the model itself. DL models have dramatically improved the state-of-the-art in many different sectors and industries, including agriculture. Deep Neural Networks (DNN) are simply an ANN with multiple hidden layers between the input and output layers.

\section{Review}

This section focuses on the state-of-the-art study based on algorithms to extract high level or low-level features associated with land, vegetation and soil information from the remotely sensed images to further perform classification. In image processing the sources of radiation include Gamma ray imaging, X-ray imaging, imaging in UV band, imaging in visible band and IR band, imaging in Microwave band and imaging in Radio band. [19]. There are a number of challenges associated with the use of remote sensing to find objects of interest using image processing. Sensor systems have a specific instantaneous field of view (IFOV) or ground-projected instantaneous field of view (GIFOV) - which is simply: a certain spatial resolution. Hence, with the improvement in spatial resolution, the area of the smallest pixel decreases, and the homogeneity of soil or crop or land characteristics within that pixel increases. [20]. In this paper, we explore three different sections- Land, soil and vegetation, where the image processing techniques have taken place. The goal of this literature review is to explore the detection of usable objects from remotely sensed imagery using ML algorithms along with combining image processing and GIS functionalities in order to utilize spectral and contextual information in an integrative way. Each of the categories explores a real-world problem associated with the domain which can make use of a better image classification or feature extraction-based approach to find out objects of interest.

\subsection{Land Management}

T. Blaschke et al [21] in their study explained more about advancements in sensors to enhance features in an image for land classification. In high-resolution images, for example, each pixel is not closely related to vegetation physiognomy as a whole, and vegetation always shows heterogeneity as a result of irregular shadow or shade, gaps, vegetation patchiness or landscape complexity. While dealing with landscape patterns, the most common problem that arises is of mixed pixels. There were a huge number of proposed possible solutions in addressing the above problem by segmentation. Although the techniques are well developed and sophisticated variations include soft classifiers, sub pixel classifiers and spectral unmixing techniques, it is argued that they do not make use of spatial concepts. Another limitation we face while dealing with problems based on land use and classifications is the problem of mixed pixels classification as discussed in the previous section of image processing. The concept of segmentation was first introduced by Haralick et al. [22] where the research presented an image analysis dealing with image semantics. In this paper, it was argued that the whole conceptual framework based on a pixel as the smallest unit of consideration is limited as long as spatial neighborhood and proximity are not considered. Another research based on monitoring change detection in land cover and land use by [23] talks about change detection, monitoring and updating based on the land cover-land use domain. These changes rely primarily upon two types of techniques: map to-map comparisons and image-to-image comparisons. Recent developments in image classification techniques like artificial neural networks (ANNs), fuzzy set methods, genetic algorithms, and support vector machines are some improved representations of the complex environments where we may not have linearly separable data points, but it solves the problem of uncertainty in segmentation and helps to extract finer details of the textured images like smoothness which can help in differentiating the land cover better. Table 1 depicts a summary of the neural network-based modelling approaches followed in recent years to extract important features from the image. 
Table 1. A review of the algorithms used for Land Management applications

\begin{tabular}{|c|c|c|c|c|c|}
\hline $\begin{array}{l}\text { Application } \\
\text { Area/Goal }\end{array}$ & Current state of art & Model & Advantages & Accuracy & Source \\
\hline $\begin{array}{l}\text { Land cover } \\
\text { classification }\end{array}$ & $\begin{array}{l}\text { Recent work has focused on } \\
\text { including context into the } \\
\text { classification process by } \\
\text { using context features } \\
\text { (Hermosilla et al., 2012) } \\
\text { and Markov or Conditional } \\
\text { Random } \\
\text { Fields (CRF) } \\
\text { (Montanges et al., 2015; } \\
\text { Novack and } \\
\text { Stilla, 2015; Albert et al., } \\
\text { 2017) }\end{array}$ & $\begin{array}{l}\text { Convolution } \\
\text { Neural } \\
\text { Networks } \\
\text { (CN } \\
\text { N) }\end{array}$ & $\begin{array}{l}\text { Traditional pixel-based machine } \\
\text { learning methods and the object- } \\
\text { based methods have an average } \\
\text { classification accuracy of } 80 \% \text {, } \\
\text { whereas most of the reviewed } \\
\text { deep learning methods achieve } \\
\text { around } 85 \% \text { classification } \\
\text { accuracy. Precisely, } 85.7 \% \text { and } \\
77.4 \% \text { can be achieved for land } \\
\text { cover and land use, respectively }\end{array}$ & $85.6 \%$ & {$[38]$} \\
\hline $\begin{array}{l}\text { High } \\
\text { Precision } \\
\text { Agriculture }\end{array}$ & 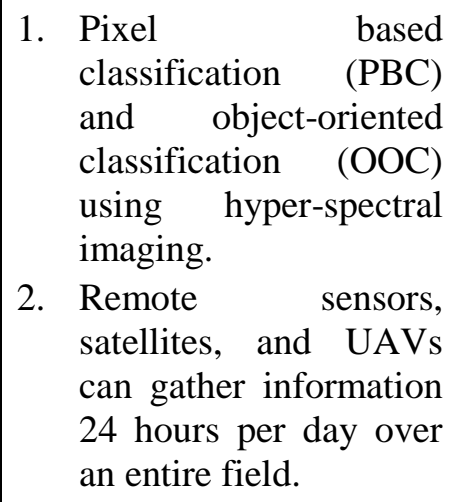 & $\begin{array}{l}\text { SVM } \\
\text { (Support } \\
\text { Vector } \\
\text { Machine) }\end{array}$ & $\begin{array}{l}\text { Supervised learning rate } \\
\text { increased the overall accuracy to } \\
92 .\end{array}$ & $92 \%$ & [39] \\
\hline $\begin{array}{l}\text { Plant } \\
\text { Phenotyping }\end{array}$ & $\begin{array}{l}\text { Existing classification } \\
\text { methods include supervised } \\
\text { pixel oriented and object- } \\
\text { oriented classification } \\
\text { based on image } \\
\text { segmentation in precision } \\
\text { agriculture using } \\
\text { hyperspectral images. }\end{array}$ & SVM, CNN & $\begin{array}{l}\text { The results achieved were fast } \\
\text { and accurate for every crop type. }\end{array}$ & $\begin{array}{l}\text { SVM } \\
\text { accuracy: } \\
94 \%, \\
\text { CNN } \\
\text { accuracy: } \\
73 \%\end{array}$ & [40] \\
\hline
\end{tabular}




\subsection{Soil Management}

The accurate estimation of soil properties from the remotely sensed imagery can help analysts to achieve good quality soil management. There are a number of challenges associated with soil research. Diversity in grasslands as spatially displayed change in soil and crop characteristics as well as the temporarily displayed variability of such irregularly distributed characteristics. The main aim of precision agriculture is to focus on reducing the uncertainty in decisions required to control variation on farms. Future research should be able to focus on linking different sensor approaches using networks within and between processes rather than focusing on the development of individual sensor systems. The first study in this category was 'farming by soil' claimed by Larson \& Robert [24] in their research and the second one was "Soil Sampling Management Zone" in [25], [26] and [27] in their respective researches. A third approach to precision agriculture began to emerge in the early 1990's known as proximal soil sensing. This approach involved spatial variability in soil properties using sensors mounted on tractors. Due to variations in spatial and temporal features, we can't expect the same soil to be present in all the areas. Hence, advancements in sensor technology is required to improve the spectral features of the image, helping the analysts to study in detail. The second study by [28] was developed for the prediction of soil condition. The study presented the comparison of four regression models for the prediction of soil organic carbon (OC), moisture content (MC), and total nitrogen (TN). The authors used a visible-near infrared (VIS-NIR) 2spectrophotometer to collect soil spectra from 140 unprocessed and wet samples of the top layer of Luvisol soil types. The last study [29] presented a novel method for the estimation of soil moisture, based on ANN models using data from force sensors on a no-till chisel opener. The table shown below depicts an overview of the machine learning classifiers or ANNs used to extract objects of interests from the soil images collected.

Table 2. AI based image processing methods applied on Soil management application

\begin{tabular}{|c|c|c|c|c|c|}
\hline $\begin{array}{c}\text { Soil } \\
\text { property }\end{array}$ & Features Observed & Model & Goal & Accuracy & Source \\
\hline $\begin{array}{c}\text { Soil } \\
\text { condition }\end{array}$ & $\begin{array}{c}\text { soil samples from top soil } \\
\text { layer of an arable field }\end{array}$ & SVM & Prediction of soil OC, MC & $\begin{array}{c}\text { RMSE }= \\
0.062 \%\end{array}$ & {$[41]$} \\
\hline $\begin{array}{c}\text { Soil } \\
\text { temperature }\end{array}$ & $\begin{array}{c}\text { Daily } \\
\text { air } \\
\text { temperature }\end{array}$ & ANN & $\begin{array}{c}\text { Detection and mapping of } \\
\text { the weed: Silybum } \\
\text { marianum }\end{array}$ & $\begin{array}{c}\text { accuracy } \\
\text { actaras }\end{array}$ & {$[42]$} \\
\hline Soil moisture & $\begin{array}{c}\text { Force acting on the chisel } \\
\text { and speed. }\end{array}$ & $\begin{array}{c}\text { ANN/MLP (Multi- } \\
\text { Layer Perceptron) }\end{array}$ & $\begin{array}{c}\text { Prediction of soil moisture } \\
\text { RMSE }=\end{array}$ & {$[43]$} \\
\hline
\end{tabular}

\subsection{Crop Management}

Aggelopoulou, A. D., et. al [30] study the variability in flower density using image processing and correlates it with the fruit yield. An apple orchard in Greece was chosen as a case study for the analysis as it is the fourth most important tree crop after olive, citrus and peach. The objective of the research is to use an image processing algorithm by MATLAB to predict tree yield by analyzing the picture of the tree at full bloom. The methodology presented is not scalable as it is just limited to a sample space of a group of 10 trees at a time. Additionally, in order to create the yield map, the geographical position of the middle tree was recorded using a handheld computer with GPS and sampling using a hand-held commercial RGB digital camera. This results in an increase in manual load. The future goal should be to improve the data quality by minimizing the 
error while capturing images. The research analysis concluded with an $18 \%$ error in predicted yield. Saxena, L. et. al [31] research reiterates the idea of precision agriculture to be a region-specific farming technique by including data from image databases, which in turn can be used to assist by providing high resolution pictures to be used for decision-making. The process of image analysis begins with grayscale conversion of the images, which is a major application to food quality. In addition to the conversion, image histogram analysis can provide us with information on where the majority of defects lie through dark or black spots with low proportion and no significant peak in the gray level histogram. The main barrier in the development of image processing in the field of agriculture is the limited data sets available for the analysis. There is a need for agricultural databases that will help develop more image processing techniques. De Baerdemaeker, J. et. al [32] research focuses on the increase in agriculture products on a global scale, there comes a growing concern about their food quality and safety. This research is concerned with good agricultural practices using the technologies of precision agriculture, including automation and robots with an aim of minimal environmental impact. In Schellberg, J., et. al's [33] paper the authors talk about how Precision Agriculture over the years has affected grasslands -plant communities that are based on grasses and herbs, in which shrubs are rare and trees are absent. The authors conclude from intensive literature screening that robust decision support systems need to be developed in order to improve the applicability of PA in grasslands. In another study [34], the authors developed a model for the estimation of grassland biomass (kg dry matter/ha/day) based on ANNs and multi-temporal remote sensing data. Another study dedicated to yield prediction, and specifically to wheat yield prediction, was presented [35]. Their method used satellite imagery and received crop growth characteristics fused with soil data for a more accurate prediction. The authors of [36] presented a method for the detection of tomatoes based on EM and remotely sensed red green blue (RGB) images, which were captured by an unmanned aerial vehicle (UAV). Also, in the work of [37], the authors developed a method for predicting the stage of rice development based on SVM and basic geographic information obtained from weather stations in China.

Table 3. A review of the algorithms used for Crop yield detection

\begin{tabular}{|c|c|c|c|c|c|}
\hline Crop & Features Observed & Model & Goal & Accuracy & Source \\
\hline Wheat & $\begin{array}{c}\text { The normalized values of the soil } \\
\text { parameters and NDVI }\end{array}$ & ANN & $\begin{array}{l}\text { Wheat yield } \\
\text { prediction }\end{array}$ & $\begin{array}{c}81.6 \% \\
\text { accuracy }\end{array}$ & [44] \\
\hline Grass & $\begin{array}{c}\text { Vegetation indices, spectral bands } \\
\text { and NIR }\end{array}$ & $\begin{array}{l}\text { ANN/Artifici al } \\
\text { Neural Networks } \\
\quad(\text { ANFIS) }\end{array}$ & $\begin{array}{l}\text { Grassland biomass } \\
\text { estimation in } \\
\text { Moorepark and } \\
\text { Grange, } \\
\text { Ireland }\end{array}$ & $\begin{array}{c}\text { Grange: } \\
\text { RMSE = } \\
\text { 15.35, } \\
\text { Moorepark: } \\
\text { RMSE = } \\
11.07\end{array}$ & [46] \\
\hline Rice & Soil physicochemical data with yield. & $\begin{array}{l}\text { Support Vector } \\
\text { Machines (SVM) }\end{array}$ & Rice yield prediction & $\begin{array}{c}\text { Average } \\
\text { RMSE = } \\
88.3 \%\end{array}$ & [47] \\
\hline Cotton & $\begin{array}{l}\text { Short wave infrared hyperspectral } \\
\text { transmittance images depicting cotton } \\
\text { along with botanical and non-botanical } \\
\text { types of foreign matter. }\end{array}$ & SVM & $\begin{array}{c}\text { Detection and } \\
\text { classification of } \\
\text { common } \\
\text { types of botanical and } \\
\text { non-botanical foreign } \\
\text { matter }\end{array}$ & $95 \%$ accuracy & {$[48]$} \\
\hline
\end{tabular}


Table 4. A review of the algorithms used for Crop Weed Detection

\begin{tabular}{|c|c|c|c|c|}
\hline Features Extracted & Model & Goal & Accuracy & Source \\
\hline $\begin{array}{c}\text { Camera images of grass and } \\
\text { various weeds types }\end{array}$ & SVN & $\begin{array}{c}\text { The Classification methods for grass } \\
\text { vs. weed detection }\end{array}$ & $\begin{array}{c}95.1 \% \text { for mixed weed and } \\
\text { mixed weather conditions }\end{array}$ & {$[50]$} \\
\hline $\begin{array}{c}\text { Spectral bands of red, green, } \\
\text { and NIR }\end{array}$ & ANN & $\begin{array}{c}\text { Detection and mapping of the weed: } \\
\text { Silybum marianum }\end{array}$ & $98.87 \%$ accuracy & {$[51]$} \\
\hline
\end{tabular}

\section{Discussions and Conclusion}

There are around 50 articles reviewed in this paper. The largest number of articles (i.e., 24 articles) are related to applications of ML in crop yield management. As shown in Figure 1, the trend in the distribution of applications is skewed toward crop and land management. The figure depicts a density visualization of the papers reviewed in the domain of Image processing using artificial intelligence-based techniques to extract the objects of interests in the Agricultural-industry. The analysis is done using the bibliometric analysis of publications to give a better idea about the distribution of papers covering the aforementioned area. The dense yellow color on the words "images", "features", depict the high use of spectral and spatial feature extraction. In ML classifier-based models, it was observed that features can be extracted without the need for fusion of data from other resources. Overall, we can conclude that remotely sensed image processing with artificial intelligence algorithms will improve the economic performance, general performance, coordination performance and robust performance of agricultural automation systems. Through the application of cutting-edge technologies such as Deep learning, Machine learning and spectral analysis, agricultural automation equipment and systems will be developed in a more intelligent way. [52]

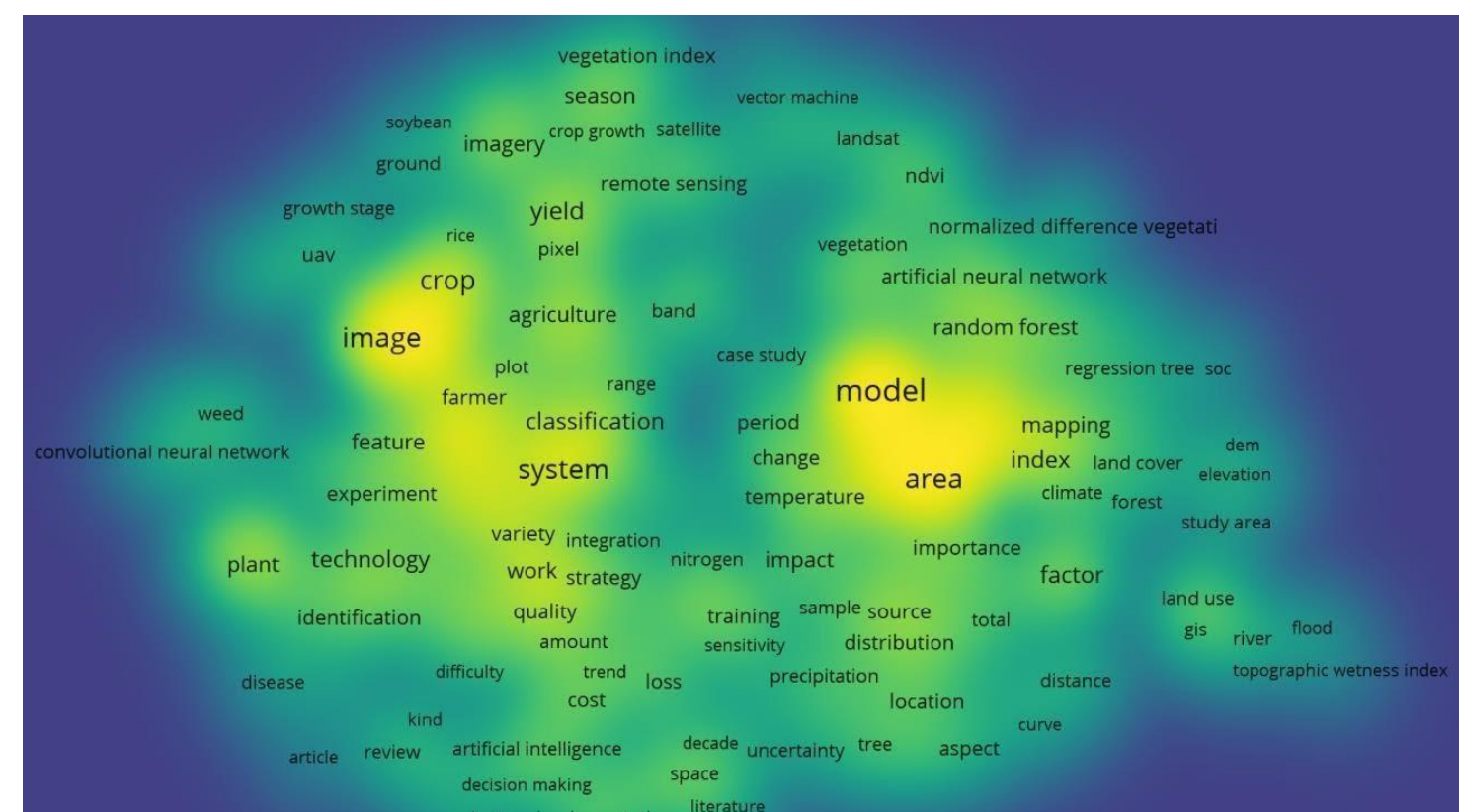

Fig. 1. Density visualization of the papers in the field of Image processing using Artificial Intelligence. 


\section{References}

[1] Abbott, J. (2019). Politics and poverty: a critique of the Food and Agriculture Organization of the United Nations. Routledge.

[2] Gorte, B. (1998). Probabilistic segmentation of remotely sensed images. ITC

[3] Ichoku, C., Deffontaines, B., \& Chorowicz, J. (1996). Segmentation of digital plane curves: a dynamic focusing approach. Pattern Recognition Letters, 17(7), 741-750.

[4] Bezdek, J. C., Ehrlich, R., \& Full, W. (1984). FCM: The fuzzy c-means clustering algorithm. Computers \& Geosciences, 10(2-3), 191-203.

[5] Joshi, A., \& Krishnapuram, R. (1998, June). Robust fuzzy clustering methods to support web mining. In Proc. Workshop in Data Mining and knowledge Discovery, SIGMOD (pp. 15-1).

[6] Chen, M. S., \& Wang, S. W. (1999). Fuzzy clustering analysis for optimizing fuzzy membership functions. Fuzzy sets and systems, 103(2), 239-254.

[7] Civico, D. L. (1993). Artificial neural networks for land-cover classification and mapping. Int. Journal of Geographic Information Systems, 7, 173-183.

[8] Foschi, P. G., \& Smith, D. K. (1997). Detecting subpixel woody vegetation in digital imagery using two artificial intelligence approaches. Photogrammetric engineering and remote sensing, 63(5), 493-499.

[9] Ardö, J., Pilesjö, P., \& Skidmore, A. (1997). Neural networks, multitemporal Landsat Thematic Mapper data and topographic data to classify forest damages in the Czech Republic. Canadian Journal of Remote Sensing, 23(3), 217-229.

[10] Chang, J. (2006). Segmenting tourists to aboriginal cultural festivals: An example in the Rukai tribal area, Taiwan. Tourism Management, 27(6), 1224-1234.

[11] Morellos, A.; Pantazi, X.-E.; Moshou, D.; Alexandridis, T.; Whetton, R.; Tziotzios, G.; Wiebensohn, J.; Bill, R.; Mouazen, A.M. Machine learning based prediction of soil total nitrogen, organic carbon and moisture content by using VIS-NIR spectroscopy. Biosyst. Eng. 2016, 152, 104- 116.

[12] Gahegan, M. N. (1999). Characterizing the semantic content of geographic data, models, and systems. In Interoperating Geographic Information Systems (pp. 71-83). Springer, Boston, MA.

[13] Stentz, A., Ollis, M., Fitzpatrick, K., Hoffman, R., \& Whittaker, W. (1999). U.S. Patent No. 5,911,669. Washington, DC: U.S. Patent and Trademark Office.

[14] Jain, A. K., \& Farrokhnia, F. (1991). Unsupervised texture segmentation using Gabor filters. Pattern recognition, 24(12), 11671186.

[15] Mao, J., \& Jain, A. K. (1992). Texture classification and segmentation using multiresolution simultaneous autoregressive models. Pattern recognition, 25(2), 173-188.

[16] Hoffman, E. A., Gnanaprakasam, D., Gupta, K. B., Hoford, J. D., Kugelmass, S. D., \& Kulawiec, R. S. (1992, June). VIDA: An environment for multidimensional image display and analysis. In Biomedical Image Processing and Three-Dimensional Microscopy (Vol. 1660, pp. 694-711). International Society for Optics and Photonics.

[17] Bengio, Y., Goodfellow, I., \& Courville, A. (2017). Deep learning (Vol. 1). MIT press.

[18] LeCun, Y., Bengio, Y., \& Hinton, G. (2015). Deep learning. nature, 521(7553), 436-444.

[19] Lillesand, T., Kiefer, R. W., \& Chipman, J. (2015). Remote sensing and image interpretation. John Wiley \& Sons.

[20] von Bueren, S. K., Burkart, A., Hueni, A., Rascher, U., Tuohy, M. P., \& Yule, I. J. (2015). Deploying four optical UAV-based sensors over grassland: challenges and limitations. Biogeosciences, 12(1), 163-175.

[21] Otukei, J. R., \& Blaschke, T. (2010). Land cover change assessment using decision trees, support vector machines and maximum likelihood classification algorithms. International Journal of Applied Earth Observation and Geoinformation, 12, S27-S31.

[22] Haralick, R. M., Shanmugam, K., \& Dinstein, I. (1973). Textural features for image segmentation. IEEE Trans. Syst. Man Cybern, 973, 610-621.

[23] Gámez-Virués, S., Perović, D. J., Gossner, M. M., Börschig, C., Blüthgen, N., De Jong, H. \& Scherber, C. (2015). Landscape simplification filters species traits and drives biotic homogenization. Nature communications, $6,8568$.

[24] Larson, W. E., \& Pierce, F. J. (1991). Conservation and enhancement of soil quality. In Evaluation for sustainable land management in the developing world: proceedings of the International Workshop on Evaluation for Sustainable Land Management in the Developing World, Chiang Rai, Thailand, 15-21 September 1991. [Bangkok, Thailand: International Board for Soil Research and Management, 1991].

[25] Mulla, D. J., \& McBratney, A. B. (2002). Soil spatial variability. Soil physics companion, 343373.

[26] Wollenhaupt, N. C., Mulla, D. J., \& Crawford, C. A. (1997). Soil sampling and interpolation techniques for mapping spatial variability of soil properties. The state of site-specific management for agriculture, (thestateofsites), 19-53.

[27] Murphy, P. N., Ogilvie, J., Meng, F. R., White, B., Bhatti, J. S., \& Arp, P. A. (2011). Modelling and mapping topographic variations in forest soils at high resolution: A case study. Ecological Modelling, 222(14), 2314-2332. 
[28] Morellos, A., Pantazi, X. E., Moshou, D., Alexandridis, T., Whetton, R., Tziotzios, G., ... \& Mouazen, A. M. (2016). Machine learning based prediction of soil total nitrogen, organic carbon and moisture content by using VIS-NIR spectroscopy. Biosystems Engineering, 152, 104-116.

[29] Johann, A.L.; de Araújo, A.G.; Delalibera, H.C.; Hirakawa, A.R. Soil moisture modeling based on stochastic behavior of forces on a no-till chisel opener. Comput. Electron. Agric. 2016, 121, 420- 428.

[30] Aggelopoulou, A. D., Bochtis, D., Fountas, S., Swain, K. C., Gemtos, T. A., \& Nanos, G. D. (2011). Yield prediction in apple orchards based on image processing. Precision Agriculture, 12(3), 448-456.

[31] Saxena, L., \& Armstrong, L. (2014). A survey of image processing techniques for agriculture.

[32] De Baerdemaeker, J. (2013). Precision agriculture technology and robotics for good agricultural practices. IFAC Proceedings Volumes, 46(4).

[33] Mondal, P. (2011). Critical Review of Precision Agriculture Technologies and Its Scope of Adoption in India. American Journal of Experimental Agriculture,1(3), 49-68. doi:10.9734/ajea/2011/1551-4.

[34] Ali, I.; Cawkwell, F.; Dwyer, E.; Green, S. Modeling Managed Grassland Biomass Estimation by Using Multitemporal Remote Sensing Data-A Machine Learning Approach. IEEE J. Sel. Top. Appl. Earth Obs. Remote Sens. 2016, 10, 3254-3264.

[35] Pantazi, X.-E.; Moshou, D.; Alexandridis, T.K.; Whetton, R.L.; Mouazen, A.M. Wheat yield prediction using machine learning and advanced sensing techniques. Comput. Electron. Agric. 2016, 121, 57-65.

[36] Senthilnath, J.; Dokania, A.; Kandukuri, M.; Ramesh, K.N.; Anand, G.; Omkar, S.N. Detection of tomatoes using spectral-spatial methods in remotely sensed RGB images captured by UAV. Biosyst. Eng. 2016, 146, 16-32.

[37] Su, Y.; Xu, H.; Yan, L. Support vector machine-based open crop model (SBOCM): Case of rice production in China. Saudi J. Biol. Sci. 2017, 24, 537-547.

[38] Kussul, N., Lavreniuk, M., Skakun, S., \& Shelestov, A. (2017). Deep learning classification of land cover and crop types using remote sensing data. IEEE Geoscience and Remote Sensing Letters, 14(5), 778-782.

[39] Kamilaris, A., \& Prenafeta-Boldú, F. X. (2018). Deep learning in agriculture: A survey. Computers and electronics in agriculture, 147, 70-90.

[40] Abdullahi, H. S., Sheriff, R. E., \& Mahieddine, F. (2017, August). Convolution neural network in precision agriculture for plant image recognition and classification. In 2017 Seventh International Conference on Innovative Computing Technology (Intech), Ieee, Londrés (pp. 1-3).

[41] Morellos, A.; Pantazi, X.-E.; Moshou, D.; Alexandridis, T.; Whetton, R.; Tziotzios, G.; Wiebensohn, J.; Bill, R.; Mouazen, A.M. Machine learning based prediction of soil total nitrogen, organic carbon and moisture content by using VIS-NIR spectroscopy. Biosyst. Eng. 2016, 152, 104- 116.

[42] Nahvi, B.; Habibi, J.; Mohammadi, K.; Shamshirband, S.; Al Razgan, O.S. Using self-adaptive evolutionary algorithm to improve the performance of an extreme learning machine for estimating soil temperature. Comput. Electron. Agric. 2016, 124, 150-160.

[43] Johann, A.L.; de Araújo, A.G.; Delalibera, H.C.; Hirakawa, A.R. Soil moisture modeling based on stochastic behavior of forces on a no-till chisel opener. Comput. Electron. Agric. 2016, 121, 420- 428

[44] Pantazi, X.-E.; Moshou, D.; Alexandridis, T.K.; Whetton, R.L.; Mouazen, A.M. Wheat yield prediction using machine learning and advanced sensing techniques. Comput. Electron. Agric. 2016, 121, 57-65.

[45] Amatya, S.; Karkee, M.; Gongal, A.; Zhang, Q.; Whiting, M.D. Detection of cherry tree branches with full foliage in planar architecture for automated sweet-cherry harvesting. Biosyst. Eng. 2015, 146, 3-15.

[46] Ali, I.; Cawkwell, F.; Dwyer, E.; Green, S. Modeling Managed Grassland Biomass Estimation by Using Multitemporal Remote Sensing Data-A Machine Learning Approach. IEEE J. Sel. Top. Appl. Earth Obs. Remote Sens. 2016, 10, 3254-3264

[47] Su, Y.; Xu, H.; Yan, L. Support vector machine-based open crop model (SBOCM): Case of rice production in China. Saudi J. Biol. Sci. 2017, 24, 537-547. [

[48] Zhang, M.; Li, C.; Yang, F. Classification of foreign matter embedded inside cotton lint using short wave infrared (SWIR) hyper spectral transmittance imaging. Comput. Electron. Agric. 2017, 139, 75-90.

[49] Hu, H.; Pan, L.; Sun, K.; Tu, S.; Sun, Y.; Wei, Y.; Tu, K. Differentiation of deciduous-calyx and persistent-calyx pears using hyperspectral reflectance imaging and multivariate analysis. Comput. Electron. Agric. 2017, 137, 150-156.

[50] Binch, A.; Fox, C.W. Controlled comparison of machine vision algorithms for Rumex and Urtica detection in grassland. Comput. Electron. Agric. 2017, 140, 123-138.

[51] Pantazi, X.E.; Tamouridou, A.A.; Alexandridis, T.K.; Lagopodi, A.L.; Kashefi, J.; Moshou, D. Evaluation of hierarchical selforganising maps for weed mapping using UAS multispectral imagery. Comput. Electron. Agric. 2017, 139, 224-230.

[52] Koech, R., \& Langat, P. (2018). Improving irrigation water use efficiency: A review of advances, challenges and opportunities in the Australian context. Water, 10(12), 1771. 